\title{
Residência Pedagógica: o ensino de química e o uso da experimentação como estratégia facilitadora para o aprendizado
}

Teaching Residency: chemistry teaching and use of experimentation as facilitating tool for learning process

Jéssica Teio Sousa

Greyciele Cerdeira Fonseca

Klenicy Kazumy de Lima Yamaguchi

\begin{abstract}
Resumo: $O$ objetivo deste trabalho consiste em analisar o ensino de Química na perspectiva dos discentes e avaliar a importância do uso da experimentação para a aprendizagem em Química. A atividade foi realizada em uma turma do $2^{\circ}$ ano do Ensino Médio de uma escola no interior do Amazonas como atividade de intervenção do Programa Residência Pedagógica, núcleo de Química. A pesquisa apresentou abordagem qualitativa e quantitativa, descritiva e exploratória. $\mathrm{O}$ projeto teve sua culminância em uma Feira de Ensino de Química onde os discentes puderam apresentar experimentos utilizando materiais acessíveis e de baixo custo. Os resultados demostraram que os discentes tiveram uma evolução em relação as suas concepções sobre os assuntos que haviam estudado durante o ano letivo e puderam ressignificar os conceitos de forma aplicável, proporcionando uma melhoria no aprendizado de Química. Pode-se verificar a importância da atividade de intervenção do Programa Residência Pedagógica para o ensino e as contribuições para os discentes do Ensino Médio.
\end{abstract}

Palavras-chave: Técnica de aprendizagem. Experimentação. Ensino de Química. Coari.

Abstract: The aim of this work is to analyze the teaching of Chemistry from student's perspective and to evaluate experimentation classroom for learning in Chemistry. The activity was realized with a second-year class from public school in Amazon as intervention activity by teaching Residency Program. The research is qualitative and quantitative, descriptive and exploratory approach. The project culminated in an exhibition in "Chemistry Teaching project" where students show experiments using accessible and cheap materials. The results showed that the students had evolution in their conceptions, and they could be able to construct a chemistry learning. It is possible to show the importance of the intervention activity of teaching Residency Program for chemistry education and the contributions for students.

Keywords: Learning process. Experimentation. Chemistry teaching. Coari city.

\section{Introdução}

A química é uma ciência que estuda os fatos naturais, buscando respostas para os processos químicos que ocorrem na natureza e explicando os mecanismos de transformação da matéria. Ensinar Química é, também, a 
formação de cidadãos conscientes e críticos (CHASSOT, 2000; SALESSE, 2012).

Segundo a Base Nacional Comum Curricular Comum (BNCC, 2018), o ensino de Química, assim como as demais áreas de Ciências da Natureza e suas tecnologias, deve propiciar ao discente a ampliação de aprendizagens essenciais que o permitam interpretar os fenômenos naturais, resolver situações-problema relacionados a temas abstratos e contextos complexos, e desenvolver habilidades investigativas que o possibilite uma reflexão sobre o papel social desta disciplina.

Nesse cenário, o professor é um dos protagonistas, tendo a missão de mediar um conhecimento que possa ser aplicado na transformação da sociedade, visando acesso à integração dos seus habitantes em uma perspectiva que desenvolva o conhecimento em prol da formação do cidadão mais crítico e consciente acerca do mundo a sua volta (SAVIANI, 2000; COSTA;SOUZA, 2013).

Apesar dos constantes avanços na área da Ciências e Tecnologia, o ensino dessa disciplina, em muitos locais, continua limitado às aulas expositivas, as quais os alunos apenas repetem o que lhes ensinam metodicamente. Sabe-se que não existe um método ideal, mas o que se espera é que seja utilizado estratégias que possam contribuir com o desenvolvimento do intelecto discente fazendo, assim, com que ele construa a sua própria visão de mundo por meio do conhecimento (SCHENETZLER; ANTUNES-SOUZA, 2018). De acordo com Queiroz (2004), o conhecimento deve envolver o despertar e a motivação dos discentes e ser aplicado baseando-se na realidade e na visão de mundo que eles possuem.

Propostas metodológicas diferenciadas aplicadas ao ensino de Química vêm sendo utilizadas como alternativas para o ensino tradicional, em que o discente deixa de ser mero espectador, decorando fórmulas, reações e propriedades, sem relacioná-las com a forma natural que ocorrem na natureza. Entre elas, cita-se sala de aula invertida, aula investigativa, abordagem CTSA, atividades lúdicas e experimentação (MONTEIRO; YAMAGUCHI, 2019; QUEIROZ; ROCHA; YAMAGUCHI 2018; COSTA; SOUZA, 2013). 
Embora seja uma prática secular, o uso de práticas experimentais é uma estratégica didática que permite ao estudante uma nova visão da Química, passando a compreende-la e aprecia-la por torna-la mais próxima da sua realidade.

As aulas experimentais são essenciais para que os alunos tenham um aprendizado eficiente e estruturado em diversos cursos, principalmente na área das Ciências e Biologia, pois somente neste tipo de aula os alunos utilizam os materiais, manuseiam equipamentos, presenciam fenômenos e organismos que podem ser observados a olho nu ou com a ajuda de microscópios. Além disso, nas aulas práticas, os alunos avaliam resultados, testam experimentos e, assim, exercitam o raciocínio, solucionam problemas e são estimulados ao desafio (Berezuk; Inada, 2010, p. 207).

No que se refere a aplicação destas atividades práticas, muitas escolas não têm aulas experimentais e os motivos descritos concentram-se na ausência de laboratório e falta de vidrarias e reagentes (QUEIROZ, 2004; YAMAGUCHI; NUNES, 2019). Com isso, a problemática de não haver experimentação continua.

Nessa perspectiva, os professores devem possibilitar situações didáticas que possam ser adaptadas à realidade em que ele está inserido. Partindo desse pressuposto, o uso de materiais alternativos vem sendo reportado como uma estratégica interessante e com resultados positivos na contribuição da aplicação de experimentos de Química a partir de materiais do cotidiano, criando suportes para facilitar os conhecimentos adquiridos ou construídos (SILVA; LACERDA; CLEOPHAS, 2017; FEIX; SARAIVA; KIPPER, 2012).

As aulas em que o professor usa apenas recursos didáticos limitados, como livro didático e quadro negro, nem sempre conseguem promover uma aprendizagem significativa. Em paralelo, aulas de experimentação tornam-se fundamentais para uma aprendizagem significativa (SALESSE, 2012, p. 11).

O objetivo deste trabalho foi apresentar as atividades realizadas pelos licenciandos participantes do Programa Residência Pedagógica da Universidade Federal do Amazonas, núcleo Química, nas atividades de intervenção utilizando práticas experimentais como ferramenta facilitadora para o ensino de Química no Ensino Médio. O projeto visou utilizar a 
experimentação utilizando materiais acessíveis e de baixo custo para auxiliar na aprendizagem dos alunos, além de despertar uma visão mais investigadora, crítica e motivadora nos discentes.

\section{Materiais e métodos}

A pesquisa apresentou abordagem de cunho qualitativo, com análise observacional direta sobre a evolução dos discentes e aspectos fenomenológicos

O lócus da pesquisa foi o município de Coari, Amazonas, Brasil. O projeto foi realizado com discentes de uma turma do $2^{\circ}$ ano noturno do Ensino Médio em uma escola pública da rede estadual de ensino, composta por 16 discentes com idade entre 16 e 38 anos.

O delineamento metodológico desta atividade constou em três momentos, buscando uma melhor sistematização e apresentação dos dados. Inicialmente foi aplicado o questionário inicial, contendo perguntas fechadas e abertas para averiguar o conhecimento prévio, dificuldade na disciplina de química e assuntos em que os discentes apresentavam maior facilidade.

A segunda etapa consistiu na aplicação do projeto. A turma foi dividida em quatro grupos de 4 pessoas, em que cada grupo ficou responsável para realização de um experimento específico. Os experimentos selecionados foram baseados nas práticas disponibilizadas na rede mundial de computadores (MANUAL DO MUNDO, 2013):

a) Torre de Líquidos

Objetiva: analisar a densidade dos líquidos e relacioná-los com o volume e a massa.

Materiais utilizados: 5 béqueres de $100 \mathrm{~mL}$ (copo de vidro); proveta de 200 ou 250 mL; Glucose de milho; Água; Óleo de soja; Álcool Etílico;

Querosene; 1 comprimido efervescente; corantes nas cores: azul, amarelo, verde, vermelho.

Procedimento: Adiciona-se em uma proveta $20 \mathrm{~mL}$ de glucose de milho e em seguida, acrescenta-se $20 \mathrm{~mL}$ de água previamente misturada com corante. Após, acrescenta-se o 
óleo, o álcool (misturado com outro corante) e querosene. Por fim, acrescenta-se o comprimido efervescente.

b) Lâmpada de Lavas

Objetivo: Estudar as forças intermoleculares presentes e mistura homogênea e heterogênea.

Materiais utilizados: 1 litro de óleo vegetal, corante (alimentício), comprimido efervescente antiácido, garrafa de vidro e um copo com água.

Procedimento: Adicionar a água previamente misturada com corante no óleo. Acrescentar o comprimido efervescente na mistura.

c) Revelando Impressões Digitais

Objetivo: Observar como ocorre a revelação de impressões digitais através da sublimação do iodo.

Materiais utilizados: Erlenmeyer de $250 \mathrm{~mL}$; tela de amianto; papel A4; pinça de madeira; 1 vela; fósforo ou isqueiro; tripé; lodo sólido; vidro de relógio; Lata; luvas descartáveis.

Procedimento: Com o auxílio das luvas, cortar pequenas tiras de papel A4 e reserva-las. Acrescentar sobre a lata grande, uma vela, o tripé e a tela de amianto. Adicionar o iodo no Erlenmeyer e acender a vela, esperando que ocorra a sublimação do iodo (apresenta vapor de cor violeta). Marcar as tiras de papel A4 com impressões digitais e com o auxílio da pinça de madeira, por a tira de papel dentro do Erlenmeyer. Espera-se alguns segundos até que seja revelada a impressão digital.

d) Sangue Falso

Objetivo: Apresentar as propriedades de uma substância básica (hidróxido de amônio/amoníaco comercial).

Materiais utilizados: $20 \mathrm{~mL}$ de fenolftaleína; $20 \mathrm{~mL}$ de hidróxido de amônio $\left(\mathrm{NH}_{4} \mathrm{OH}\right) ; 50 \mathrm{~mL}$ de álcool; $100 \mathrm{~mL}$ de água; Copo (ou béquer); colher ou bastão de vidro.

Procedimento: Mistura-se álcool, água e fenolftaleína. Acrescenta-se hidróxido de amônio. Utilizar a solução como o sangue falso, jogando-o em um papel ou camisa branca. Secar com o auxílio de um secador o observar a reação.

Utilizou-se os recursos tecnológicos digitais por meio do uso de vídeos, computador e Datashow para explicar os mecanismos envolvidos nos experimentos selecionados pelos discentes. 
Posteriormente foi a realização dos experimentos em sala de aula para as residentes e a professora da disciplina, servindo como uma preparação para a apresentação oficial.

Houve uma roda de conversa, respondendo as eventuais dúvidas dos alunos sobre as reações que ocorriam nos experimentos, dando dicas e orientações para a apresentação na Feira e conversando sobre a aplicação no cotidiano dos fenômenos ocorridos.

O terceiro momento foi a apresentação na I Feira de Ensino de Química, organizada pelos residentes com a parceria das preceptoras, professores e alunos da escola. $\mathrm{Na}$ atividade houve a apresentação dos experimentos e, em sequência, a explicação das reações.

Finalizando, foi aplicado o questionário final com perguntas fechadas e abertas com o intuito de avaliar as atividades desenvolvidas e a influência para o aprendizado em Química. Os discentes tiveram a oportunidade de responder uma questão subjetiva sobre a análise da atividade. Tanto o questionário inicial quanto o final tiveram a garantia do anonimato dos discentes, não sendo identificado o nome e nem a idade. Os dados coletados foram tabulados, analisados e apresentados por meio de resultados percentuais. Pôde-se inserir sobre os resultados, a análise qualitativa em consonância com a descrição observacional dos autores deste trabalho.

\section{Resultados e discussão}

Os dados que serão apresentados e discutidos a seguir foram obtidos a partir da análise das respostas do questionário inicial aplicado aos alunos.

Tabela 1: Respostas dos alunos ao questionário inicial.

\section{QUESTÕES}

SABEMOS QUE A QUÍMICA ESTÁ PRESENTE TODOS OS DIAS NA NOSSA VIDA. VOCÊ SABERIA CITAR ALGUNS EXEMPLOS DA QUIIMICA NO SEU COTIDIANO? QUAL ASSUNTO VOCÊ TEM MAIS INTERESSE?
ALTERNATIVAS

SIM

NÃO

Esporte

Educação
RESPOSTAS

73

27

40

20 
VOCÊ TEM DIFICULDADES PARA
COMPREENDER A DISCIPLINA DE
QUIIMICA?

QUAL A METODOLOGIA MAIS
UTILIZADA PELO PROFESSOR DE
QUÍMICA?

DURANTE AS AULAS DE QUÍMICA COMO VOCE AVALIARIA O SEU

APRENDIZADO NAS AULAS MINISTRADAS PELO PROFESSOR? VOCÊ GOSTARIA DE REALIZAR ATIVIDADES EXPERIMENTAIS?
Redes sociais e Tecnologia

Mercado de trabalho

Política

SIM

NÃO

Aula expositiva com auxílio de lousa e livro

Aulas com atividades experimentais

Aulas e atividades lúdicas

Aulas com tecnologias digitais

(mídia)

Ótimo

Bom

Regular

Péssimo

\section{SIM \\ NÃO}

0

7

60

Fonte: Dados primários, 2020.

A maioria dos discentes afirmaram que sabiam citar exemplos da química no seu cotidiano (73\%). Os Exemplos citados foram: "evaporação do líquido; café e temperatura; secagem de roupas; produtos de limpeza; ao fazer comida".

Ao serem questionados sobre qual assunto eles consideravam mais interessante (questão 2), notou-se um maior interesse pelo esporte (40\%), seguido de tecnologias e, de forma igualitária, educação (20\%).

Esses dados mostram que é importante que os docentes venham buscar meios para um ensino de qualidade, em busca de uma motivação para o interesse em assuntos referentes ao processo de educação.

[...] para os alunos, a sala de aula não é tão atrativa quanto os outros meios de comunicação, e particularmente o apelo da televisão. Por isso, a falta de interesse e apatia em relação à escola. A saída, então, seria ela se modernizar com o uso, por exemplo, de recursos didáticos mais atraentes e assuntos mais atuais (AQUINO, 2003, p. 62).

Ao analisar a questão 3, notou-se que mais da metade da turma sente dificuldade em compreender a disciplina de Química (53\%). As justificativas dos alunos foram relacionadas a quantidade de cálculos presentes nos 
assuntos. Analisando as justificativas dos alunos, pode-se perceber que a maioria tem dificuldade na matemática e não na química em si. Esse é um dado reportado por outros pesquisadores na área de ensino de Química.

Corroborando com os achados, Fonseca (1995, p. 217) afirma que são vários os motivos relacionados com as dificuldades para aprender essa matéria escolar, dentre eles: "[...] ausência de fundamentos matemáticos, falta de aptidão, problemas emocionais, ensino inapropriado, inteligência geral, capacidades especiais, facilitação verbal e/ou variáveis psiconeurológicas”.

Zatti, Agranionih e Enricone (2010, p. 116) afirmam que é necessário que os estudantes tenham uma boa base de Matemática para que possam entender o mundo ao seu redor e isso inclui o entendimento das disciplinas em que os cálculos matemáticos se fazem necessários, como a Química.

$\mathrm{Na}$ questão 4, notou-se que a professora da disciplina realiza muitas atividades experimentais (43\%), estando como a segunda opção mais citada, seguida da aula expositiva e com uso do livro didático (50\%). A Química é uma disciplina em que a experimentação está presente e pode ser realizada em diversos conteúdos. Segundo Silvério (2012, p. 14) trabalhar com a Química apenas com o livro, texto e o quadro negro, sem a presença de atividades experimentais, é como tentar cozinhar sem ter fogo.

Sobre a análise pessoal do conhecimento em Química, notou-se que $60 \%$ da turma afirmou apresentar um ótimo aprendizado. A resposta desta questão apresenta uma dicotomia em relação a análise da dificuldade na disciplina, em que cerca de $50 \%$ dos discentes haviam afirmado ter dificuldade para compreende-la. Ou seja, eles apresentam dificuldade, mas conseguem compreender seus princípios. No mais, $27 \%$ afirmaram que avaliavam seu aprendizado como bom, $13 \%$ como regular e nenhum dos alunos marcou ruim, o que mostra o quanto o professor se preocupa com o aprendizado dos discentes. Esses dados podem estar relacionados com a questão anterior, em que se percebe o esforço da docente responsável pela busca de aulas diferenciais, como a experimentação. 
Verifica-se que os conteúdos de química, para os discentes, são abstratos, mas ao aliá-los com a prática, o processo de compreensão do aluno pode ser facilitado. De acordo com Seré (2003, p. 39):

"Graças às atividades experimentais, o aluno é incitado a não permanecer no mundo dos conceitos e no mundo das 'linguagens', tendo a oportunidade de relacionar esses dois mundos com o mundo empírico. Compreende-se, então, como as atividades experimentais são enriquecedoras para o aluno, uma vez que elas dão um verdadeiro sentido ao mundo abstrato e formal das linguagens (apud LEIRIA; MATARUCO, 2015).

Os alunos afirmaram que já haviam realizado atividades experimentais, citando as práticas de: Equilíbrio Químico e gás carbônico. Verificou-se que a escola não possuía laboratório de química ou Ciências na sua estrutura física. No entanto, isso não impossibilitou a realização das práticas experimentais.

Rosenau e Fialho (2008) afirmam que seria muito mais fácil para as realizações das aulas de química a presença de um espaço adequado. No entanto, essa impossibilidade não deve ser um impasse para que as atividades ocorram. Quando a escola não dispõe desses materiais, cabe ao professor buscar novos caminhos para tornar a aula mais significativa.

Se não temos ainda elementos disponíveis, em termos de alternativas didáticas, para compor um novo projeto de educação e ensino para a nossa escola pública, temos certamente praticas alternativas isoladas (do lado do fazer) e fundamentação crítica consistente (do lado do pensar) que, trabalhadas em conjunto, gerarão o conhecimento necessário (CANDAU, 2011).

Quando indagados se gostariam de realizar atividades experimentais, $87 \%$ afirmaram que sim, o que mostra o interesse dos alunos em descobrir coisas novas e vivenciar novas experiências. Alguns alunos (13\%) afirmaram não gostar da atividade experimental. Isso pode estar relacionado ao fato deles preferirem a forma tradicional ou ficarem com receio de sair da zona de conforto.

De acordo com Silvério (2012), faz-se necessário que o aluno passe a ter uma visão positiva da disciplina de Química, apresentando-a como parte integrante da sua vida e fazendo-os reconhecerem-na no seu cotidiano. Com 
isso, cabe ao professor a busca por metodologias que agreguem conhecimento e envolvam os alunos que inicialmente não querem participar. Como já citado, relacionar os conteúdos de Química com as temáticas que mais chamam a atenção, pode ser uma estratégia para despertar o interesse (SILVA; LACERDA; CLEOPHAS, 2017).

Para elaboração da atividade, observou-se que os discentes ficaram inicialmente apáticos com a ideia de elaborar experimentos e apresentar para o público das outras turmas na Feira de Ensino de Química, e alguns não quiseram participar. Porém, após a formação dos grupos, seleção dos experimentos e apresentação dos vídeos com a explicação dos mecanismos, notou-se que os alunos ficaram mais motivados.

Na utilização de vídeos, como complemento da explicação das reações envolvidas nos experimentos, pode-se perceber o quanto os alunos ficaram encantados com a experimentação, com o fato deles mesmos terem a possibilidade de fazer e explicar os fenômenos que, até então, eram abstratos, aguçando, com isso, a curiosidade deles.

Então, foi proposto que eles realizassem os experimentos na sala de aula, com o intuito de aguçar o espírito investigativo sobre o assunto, estimulando-os a pesquisarem em busca de mais conhecimento. A execução dos experimentos pode ser visualizada na Figura 1. O objetivo do projeto era que os discentes estudassem sobre o assunto para que pudessem explicar o experimento, sabendo o porquê de cada ocorrência e, além disso, para que estivessem preparados para eventuais perguntas sobre o que estava ocorrendo nas reações.

Figura 1: Execução dos experimentos.
A) Impressão digital;
B) Torre de líquidos;
C) Sangue Falso.
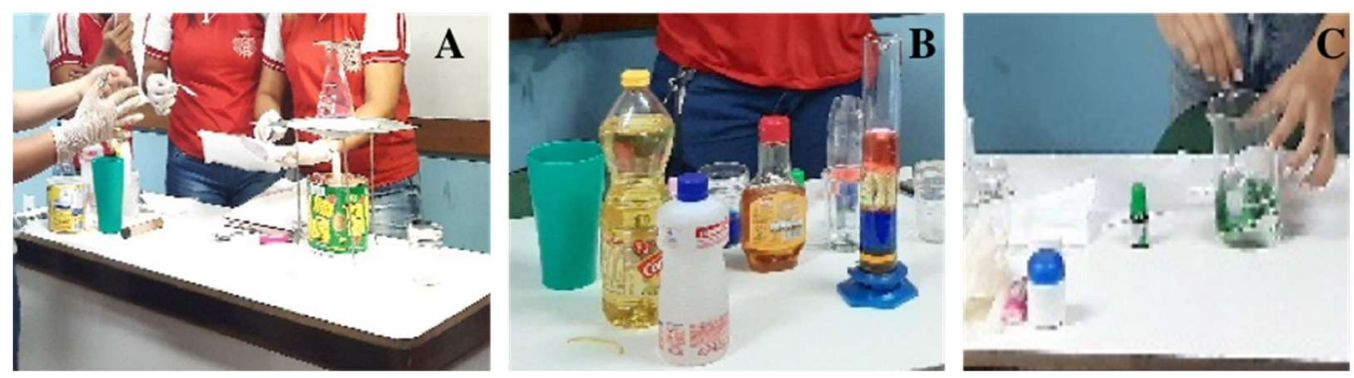

Fonte: Dados primários, 2020. 
$\mathrm{Na}$ apresentação em sala de aula, houve uma roda de conversa em que as residentes e a preceptora orientaram e deram dicas de como melhorar, além de explicar algumas dúvidas que surgiram. Apesar dos alunos terem se apresentado bem, percebeu-se que não estavam totalmente preparados para o dia da feira, além do nervosismo ter atrapalhado bastante.

De acordo com Silva; Lacerda; Cleophas (2017, p.18), as atividades quando utilizadas de forma adequada e consciente, podem proporcionar ao aluno um desenvolvimento intelectual, ou seja, proporcionar saltos qualitativos de um determinado nível de conhecimento para outro. Durante a preparação dos discentes, pode-se acompanhar a melhoria das explicações e a busca deles para o aprimoramento.

A culminância da atividade ocorreu na I Feira de Ensino de Química realizada no dia 24 de outubro de 2019. Na Figura 2 pode-se observar o evento e a execução das atividades. No evento foram realizadas diversas apresentações. $\mathrm{Na}$ exposição dos experimentos, os alunos desenvolveram a atividade com esmero e responsabilidade. Percebeu-se que eles estavam bem preparados e seguros na explicação, não deixando que o nervosismo atrapalhasse.

Figura 2: Feira do Ensino de Química.
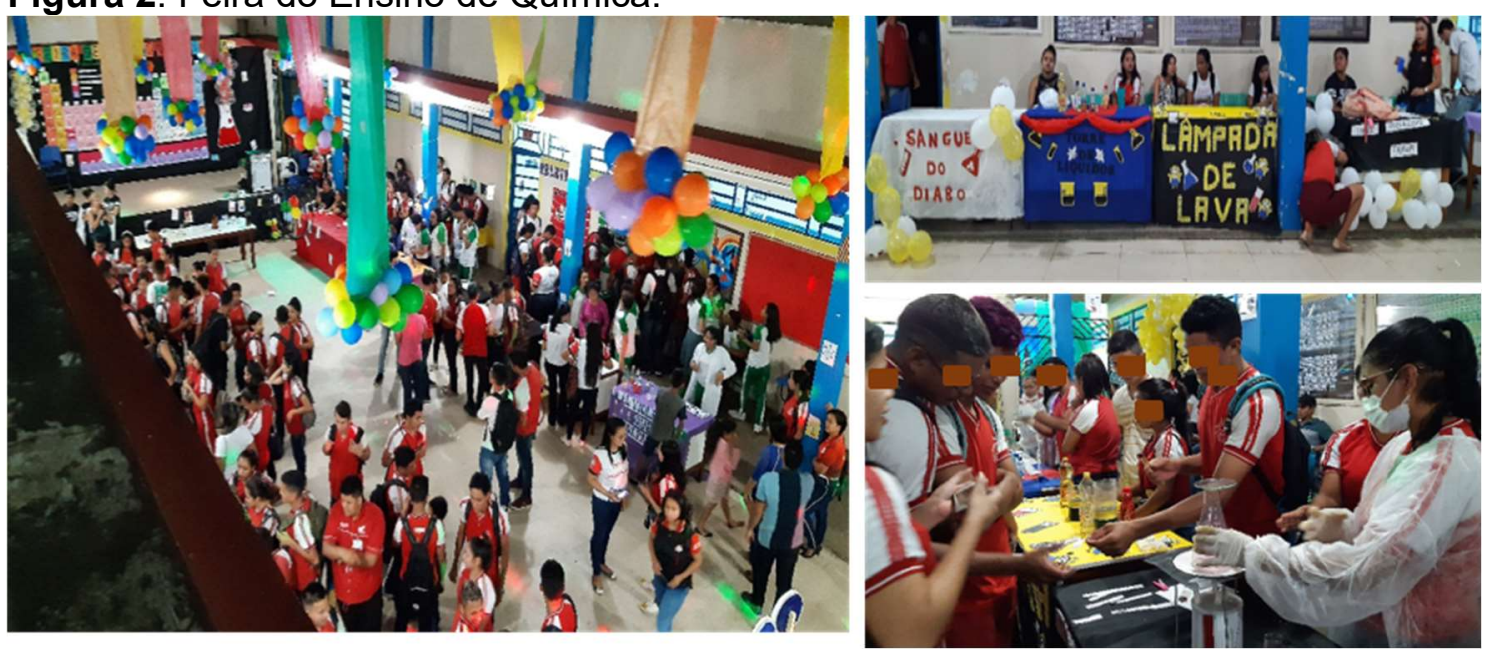

Fonte: Dados primários, 2020.

Notou-se a evolução dos alunos em relação ao prendizado e a compreensão dos mecanismos químicos. Comparando-os desde o primeiro dia, em que foi proposto a atividade, havia-se observavado pouco interesse de 
alguns discentes. No entanto, durante o desenvolvimento da atividade, essa observação foi mudando de forma gradativa. Percebeu-se a facilidade de os alunos trabalharem em grupo, no coletivo, pois dividiram a explicação e a cada rodada um dos membros realizava a demonstração do experimento e outro a explicação teórica.

De acordo com Silvério (2012, p.11), por meio da atividade prática podese despertar o interesse do aluno pela disciplina, motivando-o e fazendo-o agir por vontade própria, fazendo-o unir o que aprendeu na teoria com o que foi visto na prática, aprimorando, assim, o seu conhecimento.

Ao final de tudo, o resultado foi positivo. Os alunos relataram que gostaram bastante de terem participado, que aprenderam muito e que nunca tinham realizado experimentos dessa forma, apresentando em uma feira para outras pessoas sem ser os colegas da classe. Com a execução da prática foi possível fazer com que os alunos despertassem para o ensino de química, sendo perceptível que eles realmente aprenderam realizando e apresentando os experimentos.

Após a atividade foi realizado a avaliação por meio da aplicação do questionário final e de uma conversa com os discentes sobre os pontos positivos, negativos e a perspectiva deles em relação a execução do projeto. As respostas podem ser visualizadas na Tabela 2.

Tabela 2: Avaliação da atividade - resposta dos alunos ao questionário final.

\begin{tabular}{c|cc} 
QUESTÕES & ALTERNATIVAS & RESPOSTAS (\%) \\
\hline VOCÊ GOSTOU DA ATIVIDADE DE & SIM & 100 \\
EXPOSIÇÃO DOS EXPERIMENTOS? & NÃO & 0 \\
OS EXPERIMENTOS DESPERTARAM & & \\
O INTERESSE PELA DISCIPLINA DE & SIM & 83 \\
QUÍMICA? & NÃO & 17 \\
VOCÊ GOSTOU DO USO DE VÍDEO & SIM & 100 \\
NA DISCIPLINA DE QUÍMICA? & NÃO & 0 \\
VOCÊ SENTIU DIFICULDADE EM & & \\
RELACIONAR AS ATIVIDADES & SIM & 42 \\
EXPERIMENTAIS COM O CONTEÚDO & NÃO & 58 \\
TEÓRICO? & & \\
VOCÊ JA HAVIA PARTICIPADO DE & SIM & 75 \\
ALGUMA FEIRA DE QUÍMICA? & NÃO & 25 \\
VOCÊ GOSTARIA DE PARTICIPAR DE & SIM & 83 \\
MAIS FEIRAS DE ENSINO DE & NÃO & 17 \\
\hline
\end{tabular}




\section{QUÍMICA?}

Fonte: Dados primários, 2020.

Quando indagados se haviam gostado da exposição dos experimentos, $100 \%$ da turma afirmou que sim, o que é muito importante, pois incentiva a realização de projetos como esse, buscando atividades e metodologias diferenciadas. Segundo Maldaner e Zanon (2007), por meio da experimentação os alunos podem ser levados a formular hipóteses sobre os fenômenos ocorridos, desenvolver formas de testá-las e de modifica-las de acordo com os resultados obtidos.

Quando questionados se os experimentos despertaram o interesse pela disciplina de Química, 83\% afirmaram que sim, justificando o percentual negativo (17\%) por meio das respostas de alguns discentes:

$$
\begin{aligned}
& \text { Estudante A: Não sou fã da Química; } \\
& \text { Estudante B: Não sou muito "chegado" a Química. }
\end{aligned}
$$

De acordo com Arroio et al (2006), é consenso que a experimentação desperta o interesse dos alunos, independentemente do nível de escolarização, auxiliando no conhecimento e na consciência da importância da Química. No entanto, o conhecimento adquirido perpassa a responsabilidade do docente, tendo em vista que envolve o desenvolvimento cognitivo de cada educando.

Sobre a importância da tecnologia digital por meio da demonstração dos mecanismos dos experimentos utilizando os vídeos, $100 \%$ dos alunos afirmaram que gostaram desse recurso metodológico. Analisando os dados obtidos, nota-se o quanto é importante à aplicação de atividades diferenciadas, sendo possível a ressignificação dos conhecimentos ao vislumbra-los em uma outra perspectiva.

Oliveira (2010) afirma que as atividades experimentais podem ser abordadas de diversas maneiras, desde estratégias que apresentam uma simples ilustração ou verificação de leis e teorias, até aquelas que estimulam o aluno a buscar solução para problemas, de forma investigativa, colocando os discentes no centro do processo de construção do conhecimento. 
Em um mundo de avanços tecnológicos, a utilização de vídeos e ferramentas midiáticas é muito importante, sendo ferramentas que despertam o interessante e facilitam a visualização de acontecimentos que somente com o uso de livros e lousa tornam-se abstratos. Os conteúdos de química não devem se resumir à mera transmissão de informações e, sim, possibilitar o uso de metodologias que apresentem uma relação com o cotidiano, seus interesses e suas experiências (BNCC, 2018).

Ao analisar os dados sobre a relação dos conteúdos teóricos com a experimentação, notou-se que $58 \%$ dos alunos não sentiram dificuldade em relacionar a prática com a teoria, mas $42 \%$ afirmou que sentiu dificuldades.

É importante pensar e repensar sobre os propósitos da atividade experimental deixando claro os objetivos que deseja alcançar em cada uma das atividades, buscando realizá-la da forma mais adequada, pois uma aula experimental não deve apenas desenvolver trabalho prático, mas deve-se também trabalhar no intelecto do aluno, fazendo com que o mesmo construa seu conhecimento próprio.

Segundo Zanon e Freitas (2007), quando as atividades experimentais demonstram unicamente o que as teorias já explicam, estas atividades se tornam muito limitadas e não favorecem a construção do conhecimento.

O processo de ensino-aprendizagem dos alunos em Ciências, por meio de situações experimentais, ocorre quando, além do seu envolvimento em atividades e experiências de ensino e aprendizagem, o aluno se sente desafiado e perturbado com situações presentes no seu cotidiano e, consequentemente, instigado em buscar na literatura e com os seus colegas, usando-se de discussões e críticas, as possíveis soluções para o problema formulado (BUSATO, 2001 apud Berezuk; Inada, p. 208,2010$)$.

A maioria dos alunos (75\%) afirmou que nunca havia participado de uma Feira de Ensino de Química antes. Como já vimos, é importante levar para a sala de aula ou até mesmo para a escola atividades diferenciadas, em que ocorre a interação entre aluno-aluno e aluno-professor, proporcionando a sociabilização dos conhecimentos e contribuindo para o desenvolvimento das competências e habilidades (BORGES et al, 2016, p. 135). 
Diante do questionamento referente ao interesse em novas edições de Feiras de Ensino de Química, 83\% dos entrevistados demostraram-se positivamente favoráveis; em contrapartida, $17 \%$ afirmaram não possuir interesse em participar novamente. Por conseguinte, observa-se que a feira obteve resultados positivos, pois despertou a curiosidade e a atenção da maioria dos alunos, dos quais, em novas oportunidades, afirmaram que estariam presentes e ativos.

É preciso ter em vista que através de práticas dinâmicas, o ensino teórico torna-se tangível, mais acessível e consequentemente mais compreensível, desmistificando a complexidade da Química. Dentre a minoria que não demonstrou interesse, não se pode afirmar quais os motivos que levaram a essa resposta, haja vista que as perguntas são objetivas, mas podese destacar a falta de afinidade e/ou possuírem dificuldades com a disciplina. Esses pontos devem ser analisados e corrigidos para maior eficácia dos futuros projetos a fim de promover uma melhora na formação dos alunos.

Segundo Rosenau e Fialho (2008, p. 22), cabe ao professor o compromisso utilizar estratégias que viabilizem a aplicação de métodos pedagógicos para incentivar e despertar o interesse dos alunos para aprendizagem em Química. No entanto, sabe-se que esse é um assunto complexo e envolve outros fatores, como o pessoal, institucional e social.

$\mathrm{Na}$ avaliação sobre a aprendizagem após a realização das atividades (Figura 3), 59\% disse que foi ótima, demonstrando a boa recepção do projeto. Ao analisar os dados percebe-se que boa parte dos alunos possui uma facilidade com a disciplina, mas alguns dos alunos possuem dificuldade para compreender o conteúdo, mesmo relacionando a teoria com a prática.

Para obter uma aprendizagem mais significativa faz-se necessário partir do que o aluno já sabe. Maldaner e Zanon (2007, p. 22) afirmam que "o conhecimento não é transmitido, mas construído ativamente pelos indivíduos; aquilo que o sujeito já sabe influencia na sua aprendizagem".

Figura 3: Avaliação da aprendizagem após as atividades. 


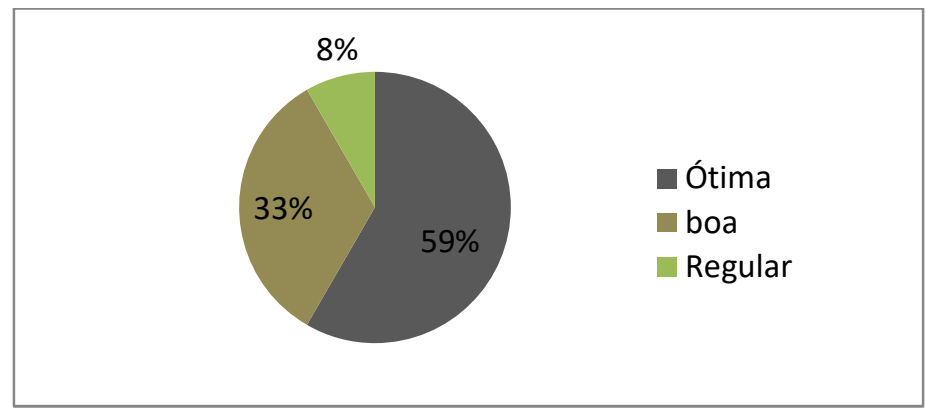

Fonte: Dados primários, 2020.

Por fim, analisou-se a questão dissertativa sobre a perspectiva dos discentes relacionada a atividade executada e a importância desta em relação a aprendizagem na disciplina de Química. Os resultados podem ser visualizados no Quadro 1.

Quadro 1: Relato sobre a experiência dos alunos frente a atividade realizada.

\begin{tabular}{|c|c|c|}
\hline Fala do Aluno 01 & Fala do Aluno 02 & Fala do Aluno 05 \\
\hline $\begin{array}{c}\text { "Foi ótima, em minha } \\
\text { opinião. Porque eu ainda } \\
\text { não tinha participado, essa } \\
\text { foi a primeira vez, espero } \\
\text { fazer muitas outras } \\
\text { vezes". }\end{array}$ & $\begin{array}{c}\text { "Bom, foi importante pra } \\
\text { mim como aprendizado. } \\
\text { Mas não é algo que me } \\
\text { interesse". }\end{array}$ & $\begin{array}{l}\text { "Foi ótimo! Eu não gostava } \\
\text { muito de Química, mais } \\
\text { depois da feira a minha } \\
\text { curiosidade despertou. Só } \\
\text { Amo a Química!" }\end{array}$ \\
\hline Fala do Aluno 08 & Fala do Aluno 11 & Fala do Aluno 12 \\
\hline $\begin{array}{c}\text { "Bem a minha foi ótima, eu } \\
\text { gostei demais aprendi } \\
\text { muitas coisas boas, e } \\
\text { também fiz os } \\
\text { experimentos, nunca } \\
\text { estive em um lugar que eu } \\
\text { me senti muito bem. Faria } \\
\text { outra vez se acontecesse } \\
\text { de novo". }\end{array}$ & $\begin{array}{c}\text { "Foi boa, por que eu } \\
\text { aprendi várias coisas } \\
\text { novas, eu me interessei } \\
\text { mais agora". }\end{array}$ & $\begin{array}{c}\text { "Foi muito boa, por que eu } \\
\text { nunca tinha participado de } \\
\text { uma feira de ciência antes, } \\
\text { e eu gostei muito, e } \\
\text { também gostaria muito de } \\
\text { participar de novo quando } \\
\text { houver oportunidades" }\end{array}$ \\
\hline
\end{tabular}

Fonte: Dados primários, 2020. 
Analisando as respostas dos alunos, observa-se o quanto foi importante o uso de atividades experimentais no ensino de química, despertando os discentes para a aplicação dos conceitos teóricos de uma forma visual. Verificou-se que alguns que não gostavam da disciplina, passaram a vê-la de uma outra forma, o que motiva tanto o professor quanto os alunos.

De acordo com Krasilchik (2012), "a motivação do professor em desenvolver os assuntos de sua disciplina e, principalmente, a realização de atividades práticas, é fator preponderante para que os alunos também se sintam motivados e valorizados"

"A motivação permitirá ao aluno se esforçar para entender tanto os conteúdos teóricos em sala de aula, quanto às atividades práticas experimentais. Por isso, a importância do professor em conduzir estas atividades para obtenção dos resultados. Isso permitirá ao aluno se sentir recompensado" (GASPAR, 2014, p. 180).

Quando questionados se as atividades auxiliaram na aprendizagem, foi unanime a resposta positiva. Esse é um dado significativo para as autoras que desenvolveram a atividade, demostrando o quanto é importante à realização de atividades experimentais para aproximar a teoria da prática, além de possibilitar a reflexão sobre como são construídos os conceitos científicos.

"A experimentação permite que os alunos manipulem objetos e ideias e negociem significados entre si e com o professor durante a aula. É importante que as aulas práticas sejam conduzidas de forma agradável para que não se torne uma competição entre grupos e, sim, uma troca de ideias e conceitos ao serem discutidos os resultados" (BUENO et al, p. 18, 2011).

Por meio da experimentação foi possível realizar um debate críticoreflexivo sobre o aprendizado e suas concepções acerca do mecanismo envolvido nas reações químicas, permitindo, assim, relembrar os conteúdos trabalhados durante o ano letivo e sanar as lacunas referentes à compreensão dos discentes. Sabe-se que a experimentação não é a única ferramenta que contribui para o ensino de Química, bem como a mera execução não garante que ocorra o aprendizado. 
No entanto, deve-se levar em consideração o papel que essa estratégia didática apresenta, motivando e ressignificando os conceitos químicos. Além disso, associada a outras metodologias como a teórica, investigativa e expositiva, bem como o uso de recursos digitais, leitura e realização de projetos, pode-se proporcionar a articulação entre o saber teórico e a aplicação social e tecnológica que a disciplina apresenta.

Para os residentes, esse foi um momento de muito aprendizado, em que foi possível vivenciar as dificuldades que os docentes encontram durante a profissão, como mediador do conhecimento e motivador dos discentes. Também pode-se ter noção de quanto é recompensador ver o desenvolvimento e construção do aprendizado e sentir que pode ser feito a diferença.

\section{Considerações finais}

A pesquisa realizada permitiu identificar a percepção dos discentes em relação ao ensino de Química. Verificou-se que os alunos gostam da disciplina, no entanto, nem sempre conseguem compreender os conteúdos, principalmente os que necessitam de uma base escolar. Pode-se observar que mesmo com atividades diferenciais, nem sempre é possível alcançar a preferência de todos os participantes, evidenciando a particularidade de cada educando.

A experimentação apresentou-se como um instrumento pedagógico útil e eficaz para o desenvolvimento dos discentes, tornando-os ativos na construção dos conhecimentos a cerca dos mecanismos envolvidos nos experimentos e aguçando a criatividade, habilidades investigativas e articulação nos trabalhos em equipe.

O objetivo da atividade de intervenção do Programa Residência Pedagógica, núcleo de Química, foram alcançados, imergindo os discentes de forma motivadora para o desenvolvimento cognitivo e intelectual de sua aprendizagem, sendo executadas práticas experimentais aplicando metodologias didáticas que reforçaram o conhecimento prévio e sanaram as lacunas dos conteúdos. 
Além disso, houve a consolidação dos graduandos em licenciatura na prática de atuação docente, confrontando com as dificuldades e benefícios da profissão. Atividades como essa são motivadas objetivando a maior ampliação das possibilidades de aplicação dos conhecimentos químicos por meio da aproximação da realidade discente.

\section{Agradecimentos}

Os autores agradecem à Capes pelo financiamento do projeto e pelas bolsas.

\section{Referências bibliográficas}

AQUINO, J. G. A indisciplina e o professor: desentranhando equívocos e malentendidos. A indisciplina na sala de aula. São Paulo: Summs, 2003.

ARROIO, A.; HONÓRIO, K. M.; WEBER, K. C.; HOMEM-DE-MELLO, P.; GAMBARDELLA, M. T. P.; SILVA, A. B. F. O show da química: motivando o interesse científico. Química Nova na Escola, v. 29, n. 1, p. 173-178, 2006.

BEREZUK, P. A.; INADA, P. Avaliação dos laboratórios de ciências e biologia das escolas públicas e particulares de Maring. Acta Scientiarum: Human and Social Sciences, v. 32, n. 2, p. 207-215, 2010.

BNCC. Base Nacional Comum Curricular. 2018. Disponível em: http://basenacionalcomum.mec.gov.br/images/historico/BNCC EnsinoMedio e mbaixa site 110518.pdf. Acesso em 24 mar 2020.

BORGES, E. E.; ALMEIDA, M. M. B.; LIMA, I. B.; SOUSA, H. M. Trilha das funções orgânicas: um jogo didático para o ensino de química. Conexão, Ciência e tecnologia, v. 10, n. 4, p. 133-140, 2016.

BUENO, L.; MOREIRA, K. C.; SOARES, M.; DANTAS, D. J; WIEZZEL A. C. S.; TEIXEIRA, M. F.S. O Ensino de Química por Meio de Atividades Experimentais: A Realidade do Ensino nas Escolas. 2011, Presidente Prudente. Anais eletrônicos [... Disponível em: http://www.unesp.br/prograd/ENNEP/Trabalhos\%20em\%20pdf\%20-\%20 de\%20Ensino/T4.pdf. Acesso em: 13 jan. 2020.

CANDAU, V. M. A didática em questão. In: ANDRÉ, E. D. A. M.; OLIVEIRA, M. R. N. S. (org.). Alternativas no ensino de Didática. 12. Ed. Campinas, SP: Papirus, 2011.

CHASSOT, A. Alfabetização Científica: questões e desafios para a educação. Juí: UNIJUÍ, 2000. 
COSTA, A. A. F.; SOUZA, J. R. T. Obstáculos no processo de ensino e de aprendizagem de cálculo estequiométrico. Amazônia - Revista de Educação em Ciências e Matemática, v.10, n.19, p.106-116, 2013.

de Santa Cruz do Sul - Santa Cruz, Rio Grande do Sul, 2012.

FEIX, E. C.; SARAIVA, S. B.; KIPPER, L. M. A importância da física experimental no processo ensino-aprendizagem. III Salão de ensino e de extensão, Universidade

FONSECA, V. Introdução às dificuldades de aprendizagem. Porto Alegre: Artes Médicas, 1995.

GASPAR, A. Atividades Experimentais no ensino de física. Uma nova visão baseada na teoria de Vigotski. São Paulo: LF editorial, 2014.

KRASILCHIK, M. Prática de Ensino de Biologia. São Paulo: USP, 2012.

LEIRIA, T. F.; MATARUCO, S. M. C. O papel das atividades experimentais no processo ensino-aprendizagem de física. $V$ Seminário Internacional sobre Profissionalização Docente. SIPD - Catedra Unesco. Anais [...], 2015.

MALDANER, O. A.; ZANON, L. B.; Fundamentos e Propostas de Ensino de Química para a Educação Básica no Brasil. 1 ed. ljuí: UNIJUÍ, 2007.

Manual do mundo, 2013. In: Manual do mundo. Disponível em: http://www.manualdomundo.com.br/ Acesso em: 11 set. 2020.

MONTEIRO, A. G. M.; YAMAGUCHI, K. K. L. O enfoque de CTS utilizando o açaí como ferramenta para o Ensino de Química. Scientia Amazonia, v. 8, p. E41-E49, 2019.

OLIVEIRA, J. R. S. A perspectiva sócio histórica de Vygotsky e suas relações com a prática da experimentação no ensino de química. Revista da educação em ciência e tecnologia, v. 3, n. 3, p. 25-45, 2010.

QUEIROZ, J. A.; ROCHA, W. C.; YAMAGUCHI, K. K. L. Atividades lúdicas como ferramenta para o ensino da teoria atômica. Scientia Amazonia, v. 7, p. E1-E6, 2018.

QUEIROZ, S. L. Do fazer ao compreender ciências: reflexões sobre o aprendizado de alunos de iniciação científica em química. Ciência \& Educação, Bauru, v. 10, n. 1, 2004.

ROSENAU, L. S.; FIALHO, N. N.; Didática e Avaliação da Aprendizagem em Química. Curitiba: Ibpex, 2008.

SALESSE, A. M. T. A experimentação no ensino de química: importância das aulas práticas no processo de ensino aprendizagem. Monografia (Especialização em Educação: Métodos e Técnicas de Ensino). Universidade Tecnológica Federal do Paraná, Medianeira, 2012. 39 fls. Disponível em: http://repositorio.roca.utfpr.edu.br/. Acesso em: 22 ago 2019. 
SAVIANI, O. Pedagogia histórico-crítica: primeiras aproximações. 7. ed. Campinas, SP: Autores Associados, 2000.

SCHENETZLER, R. P.; ANTUNES-SOUZA, T. O desenvolvimento da pesquisa em educação e o seu reconhecimento no Campo científico da química. Educação em Punto de Vista, v. 2, n. 1, p.1-19, 2018.

SERÉ, M. G.; COELHO, S. M.; NUNES, A. D. O Papel da Experimentação no Ensino de Física. In: Caderno Brasileiro de Ensino de Física. Florianópolis/BRA. v. 20, n. 1, p.31-42, 2003.

SILVA, A. C. R.; LACERDA, P. L.; CLEOPHAS, M. G.; Jogar e compreender a química: ressignificando um jogo tradicional em didático. Amazônia: Revista de Educação em Ciências e Matemáticas, v. 13, n. 28, p. 132-150, 2017.

SILVÉRIO, J. Atividades experimentais em sala de aula para o ensino de qupimica: percepção dos alunos e professor. 50p. Trabalho de Conclusão de Curso (Graduação) - Universidade Tecnológica Federal do Paraná, Pato Branco, 2012.

YAMAGUCHI, K. K. L.; NUNES, A. E. C. Dificuldade em química e uso de atividades experimentais sob a perspectiva de docentes e alunos do ensino médio no interior do Amazonas (Coari). Scientia Naturalis, v. 1, n. 2, p. 172182, 2019.

ZANON, D. A. V.; FREITAS, D. A aula de ciências nas séries iniciais do ensino fundamental: ações que favorecem a sua aprendizagem. Ciências e Cognição, v. 10, p. 93-103, 2007.

ZATTI, F.; AGRANIONIH, N. T; ENRICONE, J. R. B. Aprendizagem matemática: desvendando dificuldades de cálculo dos alunos. Perspectiva (Erechim). v. 34, n. 128, p. 115-132, 2010.

\section{Sobre os autores}

\section{Jéssica Teio Sousa}

jessicateio@outlook.com

Graduanda em Ciências: Biologia e Química no Instituto de Saúde e Biotecnologia da Universidade Federal do Amazonas, Coari, Amazonas.

\section{Greyciele Cerdeira Fonseca}

greyciele.cerdeira@gmail.com

Graduanda em Ciências: Biologia e Química no Instituto de Saúde e Biotecnologia da Universidade Federal do Amazonas, Coari, Amazonas.

Klenicy Kazumy de Lima Yamaguchi

klenicy@gmail.com 
Doutora, mestre e graduada em Química. Professora Adjunta no Instituto de Saúde e Biotecnologia da Universidade Federal do Amazonas, Coari, Amazonas. 